\title{
Luhmann, Niklas
}

\section{Das Kind als Medium der Erziehung}

Zeitschrift für Pädagogik 37 (1991) 1, S. 19-40

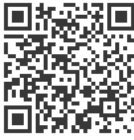

Quellenangabe/ Reference:

Luhmann, Niklas: Das Kind als Medium der Erziehung - In: Zeitschrift für Pädagogik 37 (1991) 1, S. 19-40 - URN: urn:nbn:de:0111-pedocs-118065 - DOI: 10.25656/01:11806

in Kooperation mit / in cooperation with:

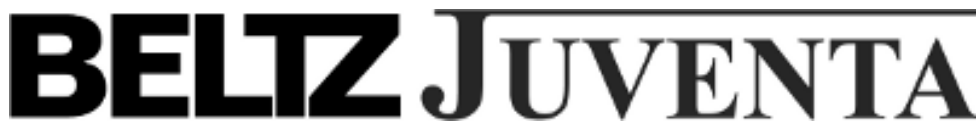

http://www.juventa.de

\section{Nutzungsbedingungen}

Gewährt wird ein nicht exklusives, nicht übertragbares, persönliches und beschränktes Recht auf Nutzung dieses Dokuments. Dieses Dokument ist ausschließlich für den persönlichen, nicht-kommerziellen Gebrauch bestimmt. Die Nutzung stellt keine Übertragung des Eigentumsrechts an diesem Dokument dar und gilt vorbehaltlich der folgenden Einschränkungen: Auf sämtlichen Kopien dieses Dokuments müssen alle Urheberrechtshinweise und sonstigen Hinweise auf gesetzlichen Schutz beibehalten werden. Sie dürfen dieses Dokument nicht in irgendeiner Weise abändern, noch dürfen Sie dieses Dokument für öffentliche oder kommerzielle Zwecke vervielfältigen, öffentlich ausstellen, aufführen, vertreiben oder anderweitig nutzen.

Mit der Verwendung dieses Dokuments erkennen Sie die Nutzungsbedingungen an.

\section{Terms of use}

We grant a non-exclusive, non-transferable, individual and limited right to using this document.

This document is solely intended for your personal, non-commercial use. Use of this document does not include any transfer of property rights and it is conditional to the following limitations: All of the copies of this documents must retain all copyright information and other information regarding legal protection. You are not allowed to alter this document in any way, to copy it for public or commercial purposes, to exhibit the document in public, to perform, distribute or otherwise use the document in public.

By using this particular document, you accept the above-stated conditions of use.

\section{Kontakt / Contact:}

DeDOCS

DIPF | Leibniz-Institut für Bildungsforschung und Bildungsinformation Informationszentrum (IZ) Bildung

E-Mail: pedocs@dipf.de

Internet: www.pedocs.de 


\section{Zeitschrift für Pädagogik}

\section{Jahrgang 37 - Heft 1 - Januar 1991}

\section{Essay}

EGON SchÜTZ

Humanismus als „Humanismuskritik“ 1

II. Thema: Theorie der Erziehung

JÜRGEN OELKERS

NikLas LuhmanN

Walter Herzog

JaN Masschelein

JAN STEUTEL

III. Diskussion

JOACHIM KAHLERT

Hartmut von Hentig
Theorie der Erziehung - Ein vernachlässigtes Thema (Einleitung zum Schwerpunkt) 13

Das Kind als Medium der Erziehung 19

Die Banalität des Guten. Zur Begründung der moralischen Erziehung 41

Die ergebnislose und die funktionslose Erziehung. Gemeinschaft, Öffentlichkeit und Immanenz 65

Konzepte und Konzeptionen. Zum Problem einer analytischen Erziehungsphilosophie 81

Die mißverstandene Krise. Theoriedefizite in der umweltpädagogischen Kommunikation 97

Gärungsprozesse statt Ablagerungen - oder: Erwartungen an ein Handbuch 123 


\section{Besprechungen}

Hans-Ulrich Grunder Jeismann, Karl-Ernst/Lundgreen, Peter (Hrsg.): Handbuch der deutschen Bildungsgeschichte. Band III. 1800-1870: Von der Neuordnung Deutschlands bis zur Gründung des Deutschen Reiches 139

Hans-Ulrich Grunder Langewiesche, Dieter/Tenorth, Heinz-Elmar (Hrsg.): Handbuch der deutschen Bildungsgeschichte. Band V. 1918-1945: Die Weimarer Republik und die nationalsozialistische Diktatur 139

ANDreas Fuitner

ANDreas Flitner

Dietrich BenNer

HANS GLÖCKEL

Heinz-Elmar Tenorth/ Christian Lüders

Heinz-Elmar Tenorth/ Christian LUUders

\section{Dokumentation}

Pädagogische Neuerscheinungen 159
WilHelm von Humboldt: Briefe an Friedrich August Wolf 144

Italien im Bannkreis Napoleons. Die römischen Gesandtschaftsbriefe Wilhelm von Humboldts an den Landgraf/Großherzog von Hessen-Darmstadt 1803-1809 144

Peter Euler: Pädagogik und Universalienstreit. Zur Bedeutung von F. I. Niethammers pädagogischer „Streitschrift" 146

Elmar Schwinger: Literarische Erziehung und Gymnasium. Zur Entwicklung des bayerischen Gymnasiums in der Ära Niethammer/ Thiersch 150

BIOS - Zeitschrift für Biographieforschung und Oral History 154

History and Memory - Studies in Representation of the Past 154 


\section{Contents}

I. Essay

EGON SCHÜTZ

Humanism as a "Critique of Humanism" 1

\section{Topic: Theory of Education}

JÜRGEN OELKERS

NiKLAS LUHMANN

Walter Herzog

Jan Masschelein

JAN Steutel

\section{Discussion}

JOACHIM KAHLERT

IV. Book Reviews

V. Documentation
Theory of Education 13

The Child as Medium of Education 19

The Banality of the Good - Towards a Foundation of Moral Education 41

Education Without Result or Function-Education, Community, the Public, and Immanence 65

Concepts and Conceptions - The Problem of an Analytic Philosophy of Education

A Crisis Misinterpreted - Theoretical Deficits in Communicating About Environmental Education 97

Hartmut von Hentig Fermentation instead of Sedimentation, or: What we expect of a manual? 123

139

159 


\section{Das Kind als Medium der Erziehung}

\section{Zusammenfassung}

Die Frage nach dem Medium der Erziehung greift eine Frage auf, die bisher eher teleologisch und psychologisch beantwortet wurde. Die Einheit der Bemühungen um Erziehung wurden an ihrem Ziel und dieses an der Zustandsveränderung der zu Erziehenden verdeutlicht. Das führt in die Schwierigkeit, daß kein Pädagoge den Innenzustand seines Zöglings, also das, was dieser während des Erzogenwerdens real erlebt, erinnert, erwartet, kennen kann. Und der Nachteil aller Teleologie ist, daß sie keinen Begriff für das doch recht typische Mißlingen der Bemühungen bereitstellt. Diese Art Theorie läßt sich durch die Unterscheidung von Medium und Form ersetzen. Über ein Medium bezieht sich ein System auf die Einheit seiner Operationen. Formen binden das Medium zu festen, aber wieder auflösbaren Einheiten. Für den Fall der Erziehung ist das Medium kein reines Kommunikationsmedium wie Geld oder Macht. Vielmehr dient als Medium die Orientierung an möglichen Bewußtseins- und Körperzuständen des Kindes, die man zu Fähigkeiten, Bildungswerten etc. zu koppeln sucht. Ein Medium fungiert immer nur systemintern, also unabhängig davon, was in den Köpfen und Körpern der Kinder auf Grund psychischer und organischer Eigendetermination faktisch vor sich geht.

I.

Unter Erziehung versteht man üblicherweise die Änderung von Personen durch darauf spezialisierte Kommunikation. Man kann diese Vorstellung einschränken - etwa durch Beschränkung auf Kinder als Gegenstand der Erziehung, also durch Voraussetzung einer Altersdifferenz zwischen Erzieher und Zögling. Üblich ist (zumindest in Pädagogenkreisen) auch, daß man, etwa unter dem Namen Freiheit, die Selbstbestimmung des Zöglings in Betracht zieht - sei es als Ziel, sei es als Schwierigkeit für die Erziehung. All diese Modifikationen des Alltagsverständnisses von Erziehung ändern jedoch nichts daran, daß der Begriff psychische Auswirkungen von Kommunikation bezeichnen soll; und zwar, im Unterschied zu Sozialisation, absichtsvoll herbeigeführte, als Verbesserung gemeinte Veränderungen psychischer Systeme. Der Begriff bezeichnet, mit anderen Worten, einen Kausalnexus, der soziale Systeme (Kommunikation) und psychische Systeme (Bewußtsein) verknüpft, und zwar auf planmäßige, kontrollierbare, wenngleich nicht immer erfolgreiche Weise verknüpft.

Läßt man sich auf diese Voraussetzung ein, kann es kein symbolisch generalisiertes Medium für Erziehung geben. Man findet daher im Erziehungssystem kein genaues Pendant zu dem, was Geld für die moderne Wirtschaft oder Wahrheit für die moderne Wissenschaft bedeutet ${ }^{1}$. Kommunikationsmedien können immer nur an sich unwahrscheinliche Kommunikation trotzdem ermöglichen. Sie können keine Außenwirkungen der Kommunikation sicherstel- 
len. Es gibt nur für Selektion, nicht aber für Erziehung einen binären Schematismus ${ }^{2}$. Es gibt im Erziehungssystem keine Technologie, die es ermöglichen könnte, Kommunikation gegen die Strukturen des Interaktionssystems $z u$ differenzieren und weitgehend unabhängig von ihnen laufen zu lassen ${ }^{3}$. Jede Gesellschaftstheorie muß derart gewichtige Unterschiede zwischen dem Erziehungssystem und anderen Funktionssystemen im Auge behalten; und wenn nicht schon die Soziologie würde erst recht die Pädagogik darauf bestehen.

Dennoch sollte dieser Ersteindruck überprüft werden. Es könnte doch sein, daß, wenn man die Problemstellung hinreichend abstrahiert, sich Parallelen entdecken lassen, denn schließlich hat auch die Erziehung es - vorläufig sagen wir: irgendwie - mit unwahrscheinlicher Kommunikation zu tun. Zumindest der Bedarf für ein symbolisch generalisiertes Kommunikationsmedium oder für funktionale Äquivalente läßt sich also nicht leugnen.

II.

Aber: wo liegt das Problem? Diese Frage muß zuerst geklärt werden.

Die alteuropäische Erziehungslehre hatte das Problem in der Verhinderung von Korruption und Verderbnis gesehen, denen das Kind, von Natur aus nach Perfektion strebend, besonders in zartem Alter ausgesetzt sei. Deshalb war Erziehung im Schutze des Hauses zu leisten, besonders unter Verantwortung und Fürsorge des Vaters. Dafür gab es sowohl religiöse als auch weltlichadelige Versionen, die auf Seelenheil bzw. tüchtige Lebensführung abstellten. Sie schlossen sich wechselseitig nicht notwendig aus.

Im 18. Jahrhundert wird jedoch nach und nach deutlich, daß ein Kind ohne Vorbestimmtheit durch seine (ständische) Herkunft zu erziehen sei. Aus jedem Kind kann nun alles Mögliche werden, und die Frage wird akut, wie in diesem Bereich offener Möglichkeiten Ordnung wiederzugewinnen sei. Die Pädagogik stellt sich von Herkunft auf Zukunft um, verliert eben damit aber die Anhaltspunkte, die in der Herkunft für die Zukunft gelegen hatten. Die modernen Erziehungslehren stellen darauf $a b$, daß die Heranwachsenden für ein Leben in der Gesellschaft ausgerüstet werden müssen mit Kenntnissen und Fertigkeiten, die sie nicht von selbst und nicht in der Familie, sondern nur in Schulen erwerben können. Diese Lehren kulminieren in der Idee der Bildung, die besagt, daß diese Teilnahmemöglichkeit an Gesellschaft, ja an Welt, dem Einzelnen als Individuum vermittelt werden müsse und daß die Individualität des Einzelnen so entwickelt werden müsse, daß er frei darüber verfügen und Teilnahme als eigene verwirklichen könne.

Beide Versionen, die alteuropäische und die neueuropäische, übersetzen ein Problem der Erwachsenen in ein Problem für Kinder ${ }^{4}$. Die Welt ist nicht so, wie sie sein sollte, also muß man erziehen. Beide Versionen übergehen ein tieferliegendes Problem. Geht man von einer Theorie selbstreferentieller autopoietischer Systeme aus, dann erscheinen sowohl psychische als auch soziale Systeme als operativ-geschlossene Einheiten, die ihre eigenen Operationen nur für die Selbstreproduktion des Systems, also nur intern, aber nicht für Aus- 
griffe in die Umwelt verwenden können ${ }^{5}$. Kein System kann ja außerhalb der eigenen Grenzen operieren, auch nicht teilweise. Jedes System kann die eigenen Strukturen nur mit eigenen Operationen aktivieren, spezifizieren, wiederaufrufen oder vergessen. Jedes System kann die eigenen Operationen nur in rekursiver Vernetzung mit eigenen Operationen produzieren und reproduzieren. Das gilt für soziale Systeme (Kommunikationssysteme) und psychische Systeme (Bewußtseinssysteme) gleichermaßen. Daher kann es auch keine operativen Überschneidungen zwischen diesen Systemen geben. Bewußt-aktuelle Aufmerksamkeit ist etwas völlig anderes als Kommunikation, obwohl jeder Beobachter feststellen kann, daß Kommunikation nicht ohne mitwirkendes Bewußtsein ablaufen kann und das Bewußtsein seine heutige Form und sein Komplexitätsvermögen nicht ohne Teilnahme an Kommunikation gewinnen könnte. Unbestritten gibt es also eine ständige strukturelle Kopplung von Bewußtseinssystemen und Kommunikationssystemen, die laufend wechselseitige Irritationen auslöst (PIAGET würde sagen: zu Assimilation und Akkommodation führt), aber trotzdem keine gemeinsame Operation und auch kein übergreifendes System. Ein Bewußtseinssystem kann sich nur durch Bewußtsein spezifizieren, ein Kommunikationssystem nur durch Kommunikation; und die rekursiven Netzwerke, über die das geschieht und deren Aktivierung das System gegen seine Umwelt differenziert, bleiben völlig verschieden. Dies und nichts anderes ist gemeint, wenn die neuere Systemtheorie von Geschlossenheit, von Autopoiesis, von strukturdeterminierten Systemen spricht.

Legt man diese Annahmen zugrunde (und eine andere Theorie würde natürlich $\mathrm{zu}$ völlig anderen Realitätsannahmen und Konsequenzen führen), erscheint das Grundproblem der Erziehung in neuem Licht. Die Theorie operativgeschlossener Systeme schließt die Annahme aus, man könne durch Kommunikation Bewußtseinsoperationen (-strukturen, -zustände, usw.) spezifizieren. Das, was der Erzieher sich vornimmt, ist unmöglich. Wie kann dann aber trotzdem erzieherische Kommunikation in Gang gebracht werden und ihre eigene Autopoiesis fortsetzen? Und: gibt es dafür ein Medium?

\section{III.}

Auch diese Frage bedarf einer begrifflichen Klärung. Auch sie gerät unter die verschärften Genauigkeitsansprüche, die sich ergeben, wenn man Systeme als operativ geschlossene, sich selbst produzierende Einheiten denkt.

Selbstverständlich ist nicht von Massenmedien die Rede. Aber auch die verbreitete Vorstellung, daß Medien einen Übertragungsvorgang vermitteln, muß aufgegeben werden. Es geht nicht darum, wie es möglich ist, etwas (zum Beispiel eine Information) von A nach B zu bringen. Es geht um Erzeugung und Reproduktion einer evolutionär unwahrscheinlichen Operationsweise, nämlich Kommunikation ${ }^{6}$. Es geht um Emergenz einer neuen Art von Realität auf der Grundlage eines vorauszusetzenden Materialitätskontinuums, das physisch-chemisch-biologisch und in unserem Falle dann auch sprachlich-gesellschaftlich vorgegeben ist. Es geht um Einzeichnen von Grenzen in dieses Kontinuum, um das Gewinnen von Form? 
Nach Vorgaben, die FrITz HeIDER für den Bereich der Wahrnehmungsmedien (also für operativ geschlossene psychische Systeme) formuliert hat, wollen wir den Begriff des Mediums (im Unterschied zu Form) gründen auf die Unterscheidung von lose gekoppelten und strikt gekoppelten Elementen ${ }^{8}$. Die lockere, weiche, formbare Struktur von Medien gibt Formen eine Chance, sich einzuprägen, sich durchzusetzen. Dabei bleibt das Medium erhalten. Es erscheint an der Form als auch anders mögliche Kopplung, als Kontingenz. Nur die Form läßt sich direkt beobachten, das Medium muß man erschließen - so wie man an den Fußspuren im Erdreich erst sieht, daß Füße fester zusammenhalten als Erde. Will man das Medium seinerseits beobachten, muß man es als Form beobachten und ein weiteres, dadurch geformtes Medium voraussetzen. Letztes, endgültig nichtbeobachtbares Medium wäre dann die Materie (im Sinne der alteuropäischen Tradition) oder, wie wir heute vielleicht sagen könnten, die Welt.

Diese Überlegungen zeigen schon, daß die Unterscheidung Medium/Form mehrfach angewandt werden kann, ja Hierarchien bildet in dem Sinne, daß das, was in einer Unterscheidung als Form fungiert, in einer anderen wieder Medium ist und höhere Formbildungen aufnehmen kann. (Eben deshalb sind wir bei einer abstrakten Vorstellung der Unterscheidung an vage Begriffe wie [relativ] lose und [relativ] strikte Kopplung gebunden.) In diesem Sinne lassen sich zum Beispiel Worte der Sprache, obwohl selbst strenge Form in einem akustischen bzw. optischen Wahrnehmungsmedium, ihrerseits als Medium verwenden; denn sie lassen weithin offen, wie sie zu Sätzen zusammengefügt, also zu strengerer Form gekoppelt werden können. Und das Beispiel zeigt auch, $\mathrm{da} ß$ die Formung das Medium nicht beseitigt oder verbraucht, sondern als immer neu formbar voraussetzt.

Für Sprache kann nach all dem gut verdeutlicht werden, daß sie als Form und als Medium zugleich fungiert. Diese geniale Eigenschaft befähigt Sprache dazu, als strukturelle Kopplung von je für sich geschlossenen Bewußtseinssystemen und Kommunikationssysteme zu dienen. Ins Bewußtsein dringt die Sprache als Formung des Wahrnehmungsmediums ein - zunächst akustisch, seit Erfindung der Schrift auch optisch. Im Zusammenhang gesellschaftlicher Kommunikation verwendet die Sprache die für Wahrnehmungszwecke gestochen scharf geformten Worte als Medium zum Gewinnen neuer Formen, eben der Sätze, deren sich die Kommunikation bedient. Natürlich haben sich nicht erst Worte, dann Sätze, erst Bewußtseinssysteme, dann Gesellschaftssysteme entwickelt. Sprache ist Bedingung und Resultat der Coevolution von psychischen und sozialen Systemen. Das aber macht nur um so mehr deutlich, daß es sich um eine hoch unwahrscheinliche evolutionäre Errungenschaft handelt, die mit der Unterscheidung Medium/Form zwar entschlüsselt und beschrieben, damit aber noch nicht genetisch erklärt werden kann.

Dies alles ist vorausgesetzt, wenn symbolisch generalisierte Kommunikationsmedien entstehen. Im typischen Falle geschieht dies über binäre Codierung. Dem positiven Wert, der die Anschlußfähigkeit der Operationen bezeichnet ${ }^{9}$, wird ein anderer Wert, ein Negativwert, ein Reflexionswert gegenübergestellt, der besagt, daß alle anschlußfähigen Operationen (alle Zahlungen, alle Macht- 
sprüche, alle kollektive bindenden Entscheidungen, alle Wissensfixierungen usw.) auch anders ausfallen könnten, ohne daß dies die Autopoiesis des Systems beenden würde. Binäre Codierung ist, mit anderen Worten, eine bedeutsame, ja die in der Gesellschaftsentwicklung führende Erfindung der Neukonstituierung eines Mediums über der immer schon in Formen und nur so benutzbaren Sprache.

Und wie macht es, wenn überhaupt, die Erziehung, wenn ihr keine Möglichkeit einer eigenen binären Codierung (außer für Selektionszwecke) zur Verfügung steht?

IV.

Wie oben in aller Kürze angedeutet, steht die Erziehung vor dem Problem, daß sie nicht kann, was sie will. Sie hat es mit psychischen Systemen zu tun, die nur das tun, was sie tun. Ein Schüler, der grinst, grinst. Ein Schüler, der rechnet, rechnet. Man kann durch Tadel oder Lob darauf kommunikativ reagieren, aber es gibt keine Möglichkeit, die Bewußtseinsverläufe, die sich daraufhin ergeben, durch Kommunikation zu spezifizieren ${ }^{10}$. Überdies handelt es sich nicht um Trivialmaschinen, die nach der immer gleichen Transformationsfunktion reagieren, sondern um selbstreferentielle Maschinen, die durch eigene Operationen selbst bestimmen, wovon sie bei der anschließenden Operation ausgehen, also von Moment zu Moment immer neue Maschinen werden ${ }^{11}$. Mit all dem handelt es sich für den Erzieher außerdem um black boxes, die er nur in ihren Externalitäten beobachten kann. Das heißt nicht zuletzt, daß der Versuch, zu kontrollieren, was hier vor sich geht, in einem Kontrolliertwerden durch diese Systeme endet ${ }^{12}$. Der Lehrer gerät, wenn er etwas erreichen will, in Zugzwang. Er muß, besonders wenn er nach einem Plan handeln will, ständig so reagieren, wie die Ereignisse es ihm vorschreiben. Und selbst wenn er sich gewisse Freiheiten nimmt, gilt das harte Gesetz, daß alle Kontrolle ein Kontrolliertwerden durch das Kontrollierte voraussetzt. Oder anders gesagt: Man kann nur in einem System Einfluß gewinnen und nur dadurch, daß man sich den Einflüssen in dem System unterwirft ${ }^{13}$. Und nun: wo gibt es hier Möglichkeiten, ein Medium zu bilden, das dank loser Kopplung durch die pädagogisch angestrebten Formen geprägt werden kann?

Die Antwort ist ebenso einfach wie überraschend, ebenso klassisch wie (in diesem Kontext) neuartig. Das Medium ist das Kind. Man muß nur davon absehen, daß es sich bei Kindern wie bei Erwachsenen, bei Babies und bei Heranwachsenden jeder Altersstufe ausnahmslos um strukturdeterminierte Systeme handelt. In allen Fällen nehmen diese Systeme nur die Zustände an, die sie sich selber verordnen, und führen nur die Operationen aus, die sie aufgrund ihrer momentanen Zustände ausführen. Das gilt für Babies mit der gleichen, ja vielleicht mit noch größerer Selbstverständlichkeit wie für Erwachsene. Es gilt ohne Ausnahme für jedermann.

Was heißt dann aber „Kind"? Wie es scheint, bezeichnet dieser Ausdruck die Erfindung des Mediums für Zwecke der Kommunikation. Seit ARlès'14 bahn- 
brechender Publikation weiß man (oder: wagt man davon auszugehen), daß das Kind eine semantische Einheit ist, die man von den Organismen und den psychischen Eigentümlichkeiten der nachwachsenden Menschen unterscheiden muß. Das Kind ist, können wir daher auch sagen, Konstrukt eines Beobachters. Man hat diese Unterscheidung Kind/organisches und psychisches System benutzt, um historische Untersuchungen zur Semantik Kind/Kindheit zu ermöglichen. Die Sinnvariabilität dessen, was unter „Kind“ explizit und implizit verstanden wird, läßt sich historisch belegen. Und wie immer umstritten die Einzelheiten sein mögen und wie immer unklar bleiben mag, seit wann es Kinder gibt: es liegt auf der Hand, daß diese Semantik für pädagogische Zwecke benötigt wird und also mit der Ausdifferenzierung von Erziehung zunächst als Rollenbesonderheit (als einfache societas) in der schon komplexen häuslichen societas, sodann als Schulerziehung - korreliert. Mit der Auffassung, das Kind sei das Medium der Erziehung, wird für solche Untersuchungen eine systematische Theorie nachgeliefert.

Offensichtlich stützt die Semantik Kind sich auf leicht erkennbare Besonderheiten dieser Wesen im Unterschied zu Erwachsenen. Ohne diesen Unterschied, der an Körpergröße und Verhalten sichtbar wird, gäbe es keine Kinder. Kinder sind das Konstrukt einer Unterscheidung. Diese Unterscheidung ermöglicht die Bezeichnung der einen Seite als Kind, und die Externalitäten dieses black box ermöglichen eine Konstruktion dessen, was ,drinnen “ vor sich gehen mag. Die Unterscheidung: Kinder sind keine Erwachsenen, Erwachsene sind keine Kinder, ersetzt gewissermaßen die (unmögliche) Aufhellung dieses black box - und es ist hierfür zunächst gleichgültig, ob Kinder nach Maßgabe der Altkybernetik (mangels requisite variety) oder nach Maßgabe der Neukybernetik (als selbstreferentielle, historische Maschinen) unerkennbar und unkontrollierbar sind. Es genügt die Vorstellung SPENCER BRowns ${ }^{15}$, daß bei jeder Unterscheidung, also auch der zwischen Kindern und Erwachsenen, ein Unterschied angenommen, eine Grenze markiert ist, so daß man nur durch Überschreiten dieser Grenze („,crossing“) von der einen Seite zur anderen gelangen, also den Anschlußpunkt für weitere Operationen verlagern kann.

Der Vorteil der Unterscheidung Kinder/Erwachsene liegt in ihrer Offensichtlichkeit, und wie immer dient Offensichtlichkeit dazu, etwas zu verdecken. Verdeckt wird, daß man die Systeme gar nicht kennt und nicht kennen kann, die so bezeichnet werden. Verdeckt wird die andere Unterscheidung von Kind (bzw. Erwachsener) und organisch-psychischen Systemen. Erst einem Beobachter der Beobachter, die die Unterscheidung Kind/Erwachsener benutzen, erst einem Beobachter der Pädagogen fällt auf, daß das Kind im Angelpunkt zweier Unterscheidungen steht. Es wird vom Erwachsenen und von den organisch-psychischen Systemen unterschieden, die als Kind (im Unterschied zum Erwachsenen) nur bezeichnet werden. Erst in der Kybernetik zweiter Ordnung, erst in der Kybernetik beobachtender Systeme läßt sich klären, daß das Kind der Erziehung als Medium dient. 
$V$

Um zu verdeutlichen, daß Kinder keine Kinder sind, selbst wenn sie so beschrieben werden, muß hier ein Exkurs eingeschoben werden, der Grundlagen einer Theorie der Sozialisation berühren wird. Die Bezeichnung Kind bezieht sich, wie zu Beginn des vorigen Abschnitts bereits angedeutet, auf eine Einheit, die sowohl über Leben als auch über Bewußtsein sich als autopoietisches System selbst reproduziert. Sowohl im organischen als auch im psychischen Sinne sind solche Systeme jeweils zustandsdeterminierte Systeme. Das heißt: sie setzen ihre eigenen Operationen im Ausgang von dem Zustand fort, in dem sie sich jeweils befinden, wobei dieser Zustand Resultat eigener vorheriger Operationen ist ${ }^{16}$. Und sie sind strukturdeterminierte Systeme in dem Sinne, daß sie für den Fortgang von Operation zu Operation Strukturen benötigen, die den Bereich der Anschlußmöglichkeiten einschränken, so daß ein Beobachter ihre Einheit durch Beschreibung ihrer Strukturen (hier zum Beispiel: Einstellungen, Gewohnheiten, Charaktermerkmale) unterscheiden und bezeichnen kann ${ }^{17}$.

Diese Charakterisierung trifft für Menschen jeden Lebensalters zu, auch für noch ungeborene; und sie trifft ausnahmslos zu. Sie widerspricht offensichtlich der Semantik „Kind", die deshalb dem zugeordnet werden muß, der sie entwirft und benutzt, um eigenes Denken oder um Kommunikation zu strukturieren. Will man erklären, weshalb Erziehung dann trotzdem erfolgreich funktioniert und sich nicht in der Welt ihrer eigenen Irrtümer festläuft, muß man bei den Systemmerkmalen zustands- und strukturdeterminierter autopoietischer Systeme und bei ihrer selbstreferentiellen Geschlossenheit ansetzen (und nicht: bei einer Hermeneutik des Sinnes von Kindheit).

Uns hilft in diesem Zusammenhang der Begriff der strukturellen Kopplung, hier: von Kommunikation und Bewußtsein. Selbstverständlich ist Kommunikation, obwohl in der eigenen Sequenz autopoietisch organisiert, nicht ohne Bewußtsein möglich. Bewußtsein kann zwar ohne Mitwirkung an Kommunikation operieren und sogar eigene Gedankensequenzen sprachförmig strukturieren $^{18}$; aber es kann nicht (oder nur in sehr rudimentärer Form) zustandekommen, wenn es nie an sprachlicher Kommunikation mitgewirkt hat. Mit einem Begriff von Humberto Maturana kann ein solcher Zusammenhang als strukturelle Kopplung bezeichnet werden ${ }^{19}$. Strukturelle Kopplungen setzen ein Materialitätskontinuum physikalischer Art voraus, das sie trägt und gemeinsames Sehen und Hören ermöglicht. Thre Grundlage liegt damit in einem anderen Medium, das die Autopoiesis von Kommunikation und von Bewußtsein ermöglicht, ohne determinierend in sie einzugreifen. Strukturelle Kopplungen sind mithin, das ist ein wesentliches Merkmal des Begriffs, mit der Autopoiesis der gekoppelten Systeme kompatibel. Sie gehen auch nicht als Strukturmoment und damit als operatives Erfordernis in die Fortsetzung der Autopoiesis ein. Auf dem Bildschirm der beteiligten Systeme werden sie nur als Irritation erkennbar, und zwar als Irritation, die mitbestimmt, was darauf geschieht.

Irritation ist ein systemspezifischer Zustand, er kann, ähnlich wie zum Beispiel 
Überraschung, nur dank der rekursiven Vernetzung von Operationen und Strukturen auftreten, mit denen das System sich selbst reproduziert. Irritation ist, mit anderen Worten, nicht etwas, was in der Umwelt schon vorhanden ist und dann in das System überführt werden kann. Die Umsetzung von strukturellen Kopplungen (hier also: von Kommunikation und Bewußtsein) in Irritationen verknüpft mithin einen System/Umwelt-Zusammenhang, den nur ein Beobachter sehen kann, mit Eigenzuständen, auf die das System autopoietisch reagieren kann und, mehr oder weniger folgenreich, reagieren muß. Strukturelle Kopplung gibt Anstoß zu einer Art Dauerirritation der Systeme; und wenn sie mit einer gewissen Dauerhaftigkeit sich wiederholt und mit einer gewissen Typizität auf das System einwirkt (etwa als Sprache), ist anzunehmen, daß sie im System Strukturentwicklungen auslöst, die ein Beobachter als gerichtet, jedenfalls als nicht zufällig erkennen kann. In den Dauerirritationen, die im Bewußtsein auftreten, wenn es sich immer wieder und in wiederholbaren Formen (Sprache) an Kommunikation beteiligt, liegt der Schlüssel für das Problem der Sozialisation. Erklärt werden kann auf diese Weise (1), daß alle Sozialisation Selbstsozialisation ist, also nicht in der Form einer Ubertragung zustandekommen kann; daß sie (2) eine über die Auslösebedingungen weit hinausgehende Vielfalt von systemeigenen Formen erzeugt, zum Beispiel in einer Familie trotz ähnlicher Bedingungen sehr verschiedene Kinder; daß sie (3) trotzdem in eine nicht zufällige Richtung führt, die es ermöglicht, daß Menschen trotz selbstreferentieller Geschlossenheit, trotz wechselseitiger Intransparenz und trotz hoher struktureller Unterschiedlichkeit sich aufeinander einstellen können; und daß (4) die Beteiligung an sprachlicher Kommunikation mit ihrer markanten, faszinierenden Formenwelt dafür das Schlüsselerlebnis ist - was immer das Einzelbewußtsein sich dabei denkt.

Sozialisation in diesem komplexen Sinne hängt vom In-Gang-Halten sprachlicher Kommunikation ab. Dafür müssen in komplexeren Gesellschaften gewisse Unwahrscheinlichkeitsschwellen überwunden werden, und dazu, nur dazu, dient im Falle von Erziehung das Medium Kind. Wenn dies so ist, wird sich kaum vermeiden lassen, daß das sogenannten Kind auf die Tatsache, daß es als solches behandelt wird, reagiert. Man sollte mehr darüber wissen, was im Bewußtsein daraufhin geschieht, wenn es registriert, daß es als Kind (oder jedenfalls: anders als Erwachsene) behandelt wird; also ob und wie die im Kontext dieser Semantik liegenden Erlaubnisse und Verbote, Freiheitskonzessionen und Vorstellungen des Könnens, Nichtkönnens, Nochnichtkönnens, Nochnichtkönnenmüssensaberdochschonkönnens, auf Strukturänderungen dieses Systems einwirken. Es wäre naiv, davon auszugehen, daß diese Effekte wie von selber der pädagogischen Intention entgegenkommen. Denn auch dann, wenn ein Bewußtsein lernt, sich selbst als Kind zu beschreiben und den kindlichen Part in der Kommunikation zu übernehmen, ist das, was daraufhin mit den Strukturen der Autopoiesis des Bewußtseins geschieht, etwas völlig anderes als das, was dadurch als Kommunikation ermöglicht oder erleichtert wird. 
$V I$.

Am Beginn der neueren Pädagogik stand der (heute verrufene) Begriff der tabula rasa, auf die gezeichnet werden müsse, was das Kind zu werden hat. Im historischen Kontext markiert er die Ablehnung von ,angeborenen Ideen“" und erst recht die Ablehnung der Moralphysik des Strebens nach Perfektion, das in der Natur angelegt sei und von Erziehern nur betreut, nur begleitet werden können ${ }^{20}$. Nein, der Mensch ist zu machen. Das ist das Signal für mehr Bemühung und mehr Verantwortung, für Ausdifferenzierung der Erziehung ${ }^{21}$.

Wir brauchen diese Diskussion nicht wiederaufzurollen, können sie aber gleichwohl als Vorgriff auf die hier gesuchte Bestimmung des Kindes ansehen. Niemand, nicht einmal Locke, hätte angenommen, daß der Mensch ein leerer Kasten sei, in den beliebige Inhalte eingefüllt werden könnten. Es ist eben nur ein schwarzer Kasten, mit dem ein Beobachter experimentieren kann. Das Kind ist Medium nur in dem Sinne, daß eine hinreichende lockere Kopplung seiner Gedanken und Vorstellungen unterstellt werden kann, die dann für Zugriffe, für formstrengere Kopplungen, insbesondere für „Wissen“ zur Verfügung stehen. „Black box" heißt dabei nur, daß nicht durchschaut und nicht kontrolliert werden kann, wie das so Identifizierte intern funktioniert. Es gibt, mit anderen Worten, ihm gegenüber keine „requisite variety“, und erst recht kann kein anderes psychisches System und kein soziales System eine einszu-eins Beziehung seiner Elemente zu denen des black box herstellen, denn das hieße, die Systeme zu einem einzigen System zu verschmelzen. Und das gilt nicht nur für externe, sondern auch und erst recht für interne Beobachtung, für Selbstbeobachtung. Für jeden Beobachter, auch für sich selbst, ist und bleibt das System intransparent.

Die Offensichtlichkeit und Ausnahmslosigkeit dieser Intransparenz gibt der Erziehung die Chance, ein Medium zu konstruieren. Das Nichtkennenkönnen (und das schließt ein, daß das beobachtete System sich selbst nicht besser, nur anders kennen kann) macht den Erziehern Mut. Sie operieren in diesem fundamentalen Sinne unwiderlegbar - was natürlich nicht ausschließt, daß sie Erfahrungen sammeln, lernen, es besser oder schlechter machen können, soweit sie ein Gedächtnis haben. Das gilt für das psychische System der Erzieher. Das gilt um so mehr für das Kommunikationssystem der Erziehung. Intransparenz ist der take off für Differenzierung und damit für die Eigenbestimmtheit der sich differenzierenden Systeme. Oder, um es zu wiederholen: eine einszu-eins Beziehung der Elemente würde, wenn erreichbar, zur Bildung eines zusammenschließenden Systems führen.

Mit Rousseaus Emile wurde das tabula rasa Konzept durch den realistischeren Begriff der Perfektibilität ersetzt ${ }^{22}$. Damit wird die als Natur postulierte Tendenz zur Perfektion aufgegeben und durch die bloße Bezeichnung einer Möglichkeit ersetzt. Darin ist Gelingen und Mißlingen vorgesehen, was immer als Erfolgskriterium eingeführt wird, und die utopische Inszenierung der Erziehung des Emile macht überdeutlich, wie unwahrscheinlich der Erfolg ist. Die Perfektibilität selbst garantiert ihn jedenfalls nicht ${ }^{23}$.

Die Pädagogen haben es anders gesehen ${ }^{24}$. Sie mußten im offenen Konzept der 
Perfektibilität einen Platz für sich selber finden, sie mußten es als ein Medium nehmen, in das man gute Absichten einpflanzen konnte. Für sie ist daher Perfektibilität die „Fähigkeit immer vollkommener zu werden als Ausstattung des Menschen im Unterschied zum Tier"25. So gefaßt erfüllt das Konzept eine Funktion für die Profession - ähnlich wie das Konzept der Erbsünde für die Theologen: Es ist schwierig, aber nicht unmöglich. Man kann Seelen retten oder junge Menschen bilden, allerdings nur mit professioneller Assistenz. Das Konzept ermutigt zu höheren Ansprüchen.

Daß die Bezeichnung Kind ein Konstrukt ist und nur so als Medium funktionieren kann, heißt also nicht, daß man beliebig vorgehen könnte. Nur muß man die Limitationen weniger in den als Kind bezeichneten organisch-psychischen Systemen suchen, als in dem System, daß diese Bezeichnung praktiziert und mit ihr Erfahrungen kondensiert. Man muß, will man wissen, wie die scheinbare Beliebigkeit der Konstruktion reduziert wird, den Beobachter beobachten und nicht das, was er beobachtet. Das Kind ist kein chemisches, kein biologisches, kein psychologisches Medium, es ist kein Kohlenstoff, kein Protein, keine Aufmerksamkeit. Es ist ein Medium nur im System der Erziehung und die Veränderungen der Konzeption dieses Mediums erklären sich deshalb durch die Ausdifferenzierung eines gesellschaftlichen Funktionssystems für Erziehung. Die nächste Frage lautet folglich: wie geht das Erziehungssystem mit seinem Medium um?

\section{VII.}

Einen ersten Einblick gewinnen wir, wenn wir auf die Zurechnungsprobleme achten, die bei allen symbolisch generalisierten Kommunikationsmedien auftauchen und jeweils unterschiedlich gelöst werden ${ }^{26}$. Hier stehen die Zurechnungsformen Handeln und Erleben zur Verfügung je nach dem, ob ein an der AuBenseite der black box erscheinendes Verhalten diesem System selbst oder seiner Umwelt zugerechnet wird. Für das Medium Kind ist bezeichnend, daß man als Erzieher die Zurechnungsform Erleben wählen muß, auch und gerade dann, wenn das Kind nach Meinung aller und nach eigener Meinung offensichtlich handelt ${ }^{27}$. Die Extravaganz (und Künstlichkeit) des Mediums Erziehung zeigt sich also darin, daß eine zunächst naheliegende Zurechnungsadressierung aufgegeben oder doch eingeklammert wird und ersetzt wird durch die Frage: wie erlebt das Kind, wenn es sich in bestimmter Weise verhält? Darin liegt nicht zuletzt eine Suspendierung des normalen moralischen Sanktionsmechanismus und die Schaffung eines Freiraums für erziehungsspezifische Sanktionen, die dann zur Ausbildung eines Selektionsmediums an Hand der Differenz von besseren oder schlechteren Leistungen führen können. Wie alle funktionsspezifischen Medien setzt auch dieses Distanz zur Moral voraus; und die Ausrede lautet hier, daß das Kind für sein Tun ",noch nicht" voll verantwortlich ist (im Unterschied zu Erwachsenen!).

Entlang der mehr oder weniger durchgehaltenen Absicht, das Kind von seinem Erleben her zu verstehen, scheint sich auch die historische Semantik der Kindheit entwickelt zu haben. Man nimmt mehr und mehr Einfühlvermögen in 
Anspruch, beobachtet das Kind als Beobachter der Welt und erkennt, daß die Welt des Kindes anders aussieht als die Welt der Erwachsenen. Das kommt zugleich der Notwendigkeit entgegen, Einwirkungsmöglichkeiten ausfindig zu machen und nicht in einer Weise zu erziehen, die das Kind weder aufnehmen noch verstehen kann. Aber während diese Einsicht auch in älteren Erziehungslehren auftaucht und sicher so alt ist wie die Reflexion der Erziehung schlechthin $^{28}$, stimuliert die Ausdifferenzierung des Erziehungssystems und die sie begleitende Reflexion eine Perspektive à la "second order cybernetics": ein Beobachten des Kindes als Beobachter und eine entsprechende Zurückhaltung von Handlungszurechnungen. Das Problem der Erziehung wird darin bestehen, nicht Handlung gegen Handlung zu setzen, sondern das Handeln nach Maßgabe des Erlebens des anderen zu wählen. Und während im Falle von Liebe das Handeln Egos so gewählt werden sollte, daß es das Erleben Alters bestätigt ${ }^{29}$, muß es im Falle der Erziehung nicht auf Bestätigung, sondern auf Korrektur abzielen.

Eine weitere Form des Entkoppelns dürfte darin liegen, daß der Erzieher das Lernen sieht und nicht das dazu nötige Verlernen oder Umlernen ${ }^{30}$. Der Erzieher unterscheidet im Unterricht Lernen vom Nichtlernen und erleichtert sich damit die Vorstellung seiner Aufgabe und die Kontrollen seiner Effekte. Im psychischen System (aber natürlich auch im Organismus, was zum Beispiel Körperhaltungen betrifft) kann dagegen Lernen und Verlernen nur als Einheit und damit ununterscheidbar praktiziert werden. Alles Gelernte muß im weiteren Lernen revidiert werden ${ }^{31}$. Die Vorstellung kumulierbaren Wissens verdeckt diesen Sachverhalt, verdeckt die psychische Komplexität des Vorgangs und damit auch das, was zur Motivation oder Demotivation weiteren Lernens beitragen könnte. Aber eben dieses Abdecken von zu viel Information wird mit der Semantik des Kindes erreicht, und das ermöglicht dem Erzieher die Vorstellung, auf Zuwachs hin zu arbeiten.

Die Summe der Fertigkeiten, Kenntnisse und Reflexionen, die an diese Kunstgriffe anschließen, stimuliert gleichsam durch die damit geschaffene Ratlosigkeit, heißt im Selbstverständnis der Profession Pädagogik.

Damit ist Einiges über das Medium ausgemacht, aber noch nichts über die Form der Form, mit der das Erziehungssystem seine Funktion erfüllt. Wir erinnern: Medium und Form sind korrelative Begriffe, zwei Seiten einer Unterscheidung, und der Unterschied besteht in der Frage, ob Elemente lose oder strikt gekoppelt sind. Die Formen, zu denen die Erziehung die Möglichkeiten ihres Mediums kontrahiert, kann man mit dem Begriff des Wisserns bezeichnen.

In der Erziehung geht es um die Vermittlung von Wissen. Es wäre falsch (oder zumindest einseitig), wenn man mit "Wissen" eine bestimmte Einstellung zur Welt, etwa eine kognitive im Unterschied zu normativen, eine rationale im Unterschied zu emotionalen, eine passive im Unterschied zu aktiven, willentlichen bezeichnen wollte. Alle diese Wissensbegriffe kommen vor, wir lassen sie beiseite. Wissen soll hier ganz allgemein die Struktur bezeichnen, mit deren Hilfe psychische Systeme ihre Autopoiesis fortsetzen, also im Ausgang von ihrem jeweils aktuellen Zustand nächste Gedanken finden, anschließen, ak- 
tualisieren können. So gefaßt, ist der Wissensbegriff ein Begriff für Redundanz, für Nichtbeliebigkeit der operativen Anschlüsse im zeitlichen Vollzug der Autopoiesis des Systems ${ }^{32}$.

Da dynamisch-stabile Systeme dieser Art sich aktuell immer in einem Zustand befinden, der sich sogleich wieder ändert, kommt auch Wissen nur im Moment vor. Das ganze System besteht aus selbstproduzierten Ereignissen, also aus den jeweils aktualisierten Sinnbezügen. Alles andere ist für das Ereignis Situation, für das Sinnsystem Welthorizont ${ }^{33}$. Es gibt also keine Wissensbestände, und Gedächtnis ist nicht als „Speicher“ zu begreifen, sondern als von Moment zu Moment neu aktualisierte Konsistenzprüfung ${ }^{34}$. (Daher brauchen wir nicht zu wissen, daß wir wissen und woher wir wissen und seit wann wir wissen, daß eine Tür mit dem Türgriff zu öffnen ist. Die Situation ist normalerweise redundant genug, das heißt: wir finden genug Anhaltspunkte für eine operationsleitende Konsistenzprüfung.) Nur ein Beobachter (aber das kann auch das operierende System selber sein) kann Wissen im Zeitschema vorstellen, also fragen und gegebenenfalls feststellen, ob man, wieso man, wie lange man schon etwas Bestimmtes weiß. Und nur ein Beobachter kann Vorstellungen über die Weiterverwendung von Wissen in künftigen Fällen bilden - aber auch er tut dies nur in dem Moment, indem er dies tut, also nur im Vollzug der eigenen Autopoiesis. Wenn Lehrer also annehmen, daß das Wissen, das sie ihren Schülern vermitteln, in deren Zukunft nützlich sein wird, ist das ihr (nur allzu verständliches) Beobachterwissen; und sie wissen es nicht, wenn sie mit etwas anderem beschäftigt sind, also etwa nachmittags ihren Garten umgraben. Alles Wissen hat eine nur temporale Aktualität, und inaktuelles (aktualisierbares) Wissen kann nur als aktuelles Wissen eines Beobachters existieren.

Mit dieser Realität dynamisch-stabiler Systeme hat es auch die Erziehung, hat es auch die Schule zu tun. Aber sie sieht davon ab. Und sie kann davon absehen, weil sie mit einer für sie spezifischen Unterscheidung von Medium und Form operiert (beobachtet). In der Erziehung und im Schulunterricht stellt man sich vor, daß Kinder Wissen erwerben und behalten oder (was sie nicht sollen) vergessen kömnen. Wissen ist, so gesehen, die Kontraktion des Mediums auf bestimmte, fest gekoppelte Formen, und man unterstellt, daß die zu erziehenden Kinder damit umgehen können (oder dies zumindest lernen sollten), wann immer es in Betracht kommt. Weitgehend wird deshalb Wissen wie eine in Situationen abrufbare Transformationsfunktion vorgestellt mit der Folge, daß immer wenn Aktualisierungsanlaß gegeben ist, dieses Wissen sinngemäß und richtig benutzt wird. Das heißt nichts anderes als daß Kinder dazu gebracht werden sollen, Trivialmaschinen zu sein, was sie nicht sein und nicht werden können ${ }^{35}$. Offensichtlich steht die Erziehung damit im Dienste sozial verlangter Zuverlässigkeit, denn nur Trivialmaschinen sind zuverlässige Maschinen, die (wenn sie nicht kaputt sind) in immer gleicher Weise Inputs in Outputs umwandeln.

Das Schema beständigen Wissens, gesehen als Form und Bindung von Möglichkeiten des Kindes, hat zahlreiche Eigenheiten, die nur deshalb übersehen werden, weil die Beständigkeit (das „Habenkönnen“) des Wissens als „offensichtlich" behandelt wird. Besondere Aufmerksamkeit verdient in diesem 
Zusammenhang die Bedeutung von Schrift. Hier geht es nicht nur um das Schreiben- und Lesenlernen im Sinne einer täglich zu brauchenden Fertigkeit, sondern um die Frage, wie diese eigentümliche Form des Wahrnehmens wirkt; und nicht nur darum, daß sie selbst als Differenz zu anderen optischen Wahrnehmungen auffällt so wie gesprochene Sprache im Medium der Akustik, sondern darum, daß sie als Form für Formbildungen, also ihrerseits als Medium dient. Schrift erschließt einen für keinen Einzelnen mehr ausschöpfbaren Möglichkeitsraum, der stabil bleibt, auch wenn die Inhalte wechseln; zwar nicht den Himmel der Himmel, aber die Form der Formen, die als Kultur dienen. Schrift „potentialisiert“ Kultur, indem sie auch Nichtgeschriebenes aufbewahrt als etwas, was man bei Bedarf schreiben könnte ${ }^{36}$. (Dies gilt in nochmals gesteigertem Maße für phonetische Schriften, die jede Illusion einer geschlossenen Welt zerstören, sobald ihre Präsenz durch Buchdruck universell wird.) Das erzwingt Selektionsmethodik, erzwingt Konsequenzenlernen, erzwingt den Übergang von situativen zu systematischen Relevanzen. Und zugleich verdekken diese Auswirkungen, weil sie der Medium-Funktion (und nicht nur der Form) von Schrift verdankt sind, das, was als Formen generierende Form in das Kind eingelassen wird $^{37}$.

Hinzu kommt die über Erziehung oktroyierte (ihrerseits schriftabhängige) Relevanz von Wahrheit. In der psychischen Autopoiesis funktioniert Wissen, wenn überhaupt, unabhängig davon, ob es sich nach Meinung von Beobachtern um wahres oder um unwahres Wissen handelt (so wie ja auch das Gehirn für wahre und für unwahre Vorstellungen nicht verschiedene neurophysiologische Prozesse bereithält). Im Unterricht wird dagegen Wert darauf gelegt, da $\beta$ man nur wahres Wissen lehrt und lernt (aber auch dies funktioniert als kommunikative Operation genau gleich und ebenso gut, wenn es sich um unwahres Wissen handelt). Operationen sind eben immer indifferent dagegen, ob ein Beobachter den gemeinten Sinn mit Hilfe der Spezialunterscheidung wahr/unwahr als wahr oder als unwahr bezeichnet ${ }^{38}$. Und man muß sagen: Zum Glück! Denn im anderen Falle würde das Schema wahr/unwahr die Autopoiesis des operierenden Systems bei nächster Gelegenheit, nämlich bei einer „unwahren" Operation mangels Anschlußfähigkeit stoppen und das System würde aufhören zu existieren. Längst wären alle Gehirne, alle Bewußtseinssysteme und erst recht alle Unterrichtssysteme verschwunden, wenn es so wäre.

Zumindest in den Schulen mutet man dem Schüler aber zu, als wahr geprüftes Wissen zu lernen. Man kann es ihm zumuten, weil man ihn als Kind (Heranwachsenden usw.) ansieht. Für die Auswahl des Stoffes genügt die Legitimation durch Wissenschaft. Wissenschaft garantiert dem Wissen aber nicht die Form, in der es psychisch und situativ eingesetzt werden kann. Daraus erklären sich frappierende Diskrepanzen zwischen Alltagskompetenz und schulischem Können. Dies gilt nicht nur für den Fremdsprachenunterricht (für den es durchaus Korrektive gibt), sondern zum Beispiel auch für den Umgang mit Algorithmen. Die Forschung hierzu steckt in den Anfängen, zeigt aber bereits deutlich, daß die Alltagskompetenz (wenn Kinder sozusagen wie Erwachsene in Anspruch genommen sind) weit höher liegen kann als das, was in Schulen als Rechnen vorgeführt und honoriert wird ${ }^{39}$. Kinder können in Spielen, auf der 
Straße oder in Jobs, Rechenoperationen durchführen, die sie in der Schule mit dort gelehrter Arithmetik nicht reproduzieren können.

Ferner kann das Oktroyieren von Formen in einem Medium immer nur selektiv erfolgen. Es nutzt bestimmte Möglichkeiten aus und stellt dadurch, daß diese bevorzugt werden, andere in den Schatten. Alles Lernen in der Schule setzt daher korrespondierende Lernverbote voraus; und angesichts der Offenheit eines Mediums muß natürlich sehr viel mehr Lernen verboten als durch Lehre freigegeben werden ${ }^{40}$.

Schließlich diskreditiert das Wissenlernprogramm eine an sich segensreiche Einrichtung dynamisch stabiler Systeme, nämlich das Vergessen. Wenn Wissen in nichts anderem besteht als in seiner aktuellen Verwendung zur Organisation der Autopoiesis, liegt auf der Hand, daß es je nach den Sequenzen der $\mathrm{Zu}-$ standsveränderungen, je nach der Geschichte der Systeme wiederbenutzt oder nicht wiederbenutzt wird. Je nach dem, wo es lang geht, unterliegt das Wissen also einer natürlichen Selektion. Was wiederbenutzt wird, kondensiert zu Erfahrung und nimmt damit eine Form an, die sich aller exakten Beschreibung entzieht. Was nicht wiederbenutzt wird, ist schließlich nicht mehr abrufbar wie alle Erfahrungen mit Alphabetisierungskampagnen in Entwicklungsländern lehren. Eine für unseren Zusammenhang wichtige Konsequenz ist: daß Erwachsene sich nicht daran erinnern können, wie es gewesen war, Kind zu sein. Sie müssen die „Welt des Kindes“ am Gegenüber neu erfinden.

Das Versinken des Nichtwiederholten erfolgt unbemerkt (Bemerken wäre Wiederholen) und hat eine wichtige Funktion für Systeme, die als strukturdeterminierte Systeme funktionieren müssen. Im Schema Medium/Form oder Kind/Wissen wird dagegen Vergessen dispräferenziert oder gar als Unheil gefürchtet und scharf zensiert.

All diese Überlegungen zeigen, daß das Medium der Erziehung eine extrem artifizielle Beobachtungsweise institutionalisiert. Deshalb ist es schwierig, damit umzugehen. Und deshalb hat die Lehre von den Möglichkeiten, es trotzdem zu tun, besondere Namen. Sie heißt auf der Seite des Mediums, wie schon gesagt, Pädagogik, auf der Seite der Form dagegen Didaktik.

\section{VIII.}

In der naturalen Pädagogik der Tradition werden Kinder nach Alter und Reifegrad unterschieden. Deshalb hatte man sie in (von heute her gesehen) relativ frühen Jahren bereits für erwachsen gehalten. In der neueren Pädagogik setzt sich dagegen heimlich eine andere Unterscheidung durch. Sie besteht in der Frage, ob Kinder lesen können oder nicht. Dabei kommt es nicht allein, das macht den Durchblick schwierig, auf die Frage an, ob Kinder die Fertigkeit des Lesens gelernt haben oder nicht oder noch nicht. Entscheidend für die Möglichkeit, an dieser Stelle zu diskriminieren, ist vielmehr der Buchdruck und die Verfügbarkeit von Büchern für das Selbstlesen vor und nach dem Unterricht. 
Traditionelle Schriftkulturen kannten natürlich auch aufgeschriebenes Wissen, aber sie benutzten es generell nur als Hilfsmittel für mündliche Kommunikation. Mündliche Kommunikation konnte sich, im Leben wie in der Schule, auf schriftlich fixierte Texte beziehen ${ }^{41}$. Sie konnte in Kenntnis und Verständnis dieser Texte Lehrautorität gewinnen. Die Lehre war als ein Übertragungsprozeß gedacht. Lernen war mechanisches Annehmen, und Verstehen des Gelehrten war ein später Lohn und Bestätigung des Erwachsenseins ${ }^{42}$. Dies ändert sich grundlegend mit dem Buchdruck ${ }^{43}$. Bücher empfehlen sich zum „Selbstlernen". Für die Schule bedeutet das, daß der Unterricht Selbstlernfähigkeiten entwickeln und dann damit rechnen kann. Lehren und Lernen sind nun völlig verschiedene Operationsweisen, und ihre trotzdem anzustrebende Integration wird zum Problem. Die daraufhin reformulierte Pädagogik mißt sich nicht mehr nur am Herüberkommen des Stoffes in die Köpfe der Kinder, sondern an der Entwicklung von Lernfähigkeit. Die „Paukschule“ gerät in Verruf. Die Schule ist nun als Bildungsinstitution gefragt. Entsprechend wird die naturale, den Alternsproze $ß$ begleitende Erziehung nur noch für eine Anfangsphase empfohlen, in der die Kinder noch Kinder sind. Und darauf folgt die Phase des Schulbesuchs und des Studiums, in der Bildung gefördert wird im Sinne einer möglichst frühen Selbständigkeit im Umgang mit der Lektüre.

Die Zäsur des Lesen- und Selbstlernenkönnens revolutioniert die Semantik der Kindheit. Sie entscheidet nicht nur darïber, was in der Schule oder in der Universität mit ausreichend entwickelten Kompetenzen geschieht. Sie wird in einer Art Rückwärtsprojektion auch auf die frühkindliche Erziehung angewandt. Auch hier soll es nun nicht mehr einfach um Dressur gehen, sondern um Lernen im educativen (darf man sagen: educagenen?) Milieu. Das Gesamtmedium Kind wird transformiert. Das Medium Kind, wie wir es heute kennen, ist ein Resultat des Buchdrucks und insofern dann auch ein genuin soziales Medium.

\section{$I X$.}

Ein gutes, für Funktionssysteme brauchbares Medium setzt voraus, daß es durch Formbildung nicht verbraucht, sondern zugleich erneuert wird. PARSONS nennt das mit einer gewagten Metapher "Zirkulation". So macht sich der Machthaber durch Machtgebrauch in der Form kollektiv bindender Entscheidungen sichtbar und stellt mit der Durchsetzung von Entscheidungen andere, ebenfalls durchsetzbare Entscheidungen in Aussicht. So verbraucht sich das Geld nicht, indem es für bestimmte Zwecke in bestimmter Höhe ausgegeben wird (also Form annimmt), sondern erneuert seine mediale Potenz im Zahlungsvorgang selbst. So sind Wahrheitsgewinne wie Unwahrheitsgewinne in der modernen Wissenschaft besonders geschätzt, wenn sie zu weiteren Forschungsfragen Anlaß geben, und wo das nicht der Fall ist, wird die Wahrheit bzw. Unwahrheit rasch uninteressant. Und im Fall der Erziehung?

Solange von „Bildung“ die Rede war (oder es noch ist), war keine Lösung dieses Problems in Sicht, und das heißt immer: keine Lösung, also kein Problem. Dies gilt offensichtlich für den Fall einer am Lesestoff kanonisierten 
Bildung, bei der es im Erziehungssystem genügt, die Kinder in die dadurch bestimmte Form zu bringen. Aber auch wenn man mit KLAFKI den Bildungsbegriff für historisch aktuelle, also wechselnde gesellschaftliche Probleme öffnet $^{44}$, ist damit nicht geklärt, wie sich das Medium trotz Formbildung regenerieren kann. Der Anstoß für Formänderungen, also Änderungen der Bildungsinhalte und Unterrichtsthemen, wird von der gesellschaftlichen Umwelt des Erziehungssystems erwartet. Das ist ein nicht zu unterschätzender Beitrag zur Erklärung der Dynamik des Systems (wenn man einmal davon absieht, da $\beta$ er im Kontext von Bildung in wertbegrifflicher Fassung formuliert ist). Der Seitenblick auf andere Medien wie Macht, Geld und Wahrheit, die selbst für ihre Regenerierung sorgen können, also eine Eigendynamik des Systems auslösen, läßt aber die Frage aufkommen, ob nicht auch das Medium des Erziehungssystems über entsprechende Möglichkeiten verfügt.

Und in der Tat: man muß nur die Formel Bildung durch die Formel Lernfähigkeit ersetzen ${ }^{45}$, um solche Möglichkeiten in den Blick zu bekommen. Die Formel Lernfähigkeit postuliert ein Prinzip der Selektion von Wissensformen, das an den Lernmöglichkeiten ausgerichtet ist, die sie vermitteln. Und Lernmöglichkeit heißt eben, daß neue, noch nicht bestimmte Kopplungsmöglichkeiten erzeugt werden. So lernt das Kind den aufrechten Gang, um auf diese Weise noch unbestimmte Lernmöglichkeiten zu gewinnen. Dergleichen durch Sprachlernen und durch Lesenlernen. Dergleichen durch alle Arten professioneller Kompetenz, die zwar nicht bestimmen, wie man sich in Situationen verhalten wird (der alte Irrtum der Suche nach anwendbarem Wissen), wohl aber situative Beobachtungen so vorstrukturieren, daß man rasch lernen und daher auch leicht auf vorgefaßte Meinungen (strikte Kopplungen) verzichten kann. Man wird darum nicht notwendigerweise bis ins hohe Lebensalter von "Kindern" sprechen ${ }^{46}$. Das Medium bleibt an die Unterscheidung von Kindern und Erwachsenen gebunden, aber es kann die Terminologie „Kind“ durch andere ergänzen (Schüler, Studenten oder schließlich: Lernende). Das ist letztlich nur ein Problem der Benennung. Entscheidend ist, daß mit Lernfähigkeit als Ziel zugleich die Wiederherstellung des Mediums durch seinen Gebrauch postuliert ist. Und wenn es zutrifft, daß man einen Wandel der Kontingenzformeln des Erziehungssystems von naturaler Perfektion über eine (nur transitorisch sinnvolle) Bildungsformel zu Lernfähigkeit hin beobachten $\mathrm{kann}^{47}$, dann ist das ein deutlicher Indikator dafür, daß das Erziehungssystem die eigene Ausdifferenzierung nicht nur auf struktureller Ebene (relative, durch strukturelle Kopplungen limitierte Autonomie), sondern auch auf operativer Ebene (Autonomie als selbstreferentielle Geschlossenheit) erreicht.

$X$.

Das Medium Kind ist nicht binär codierbar. Kinder unterscheiden sich zwar von Erwachsenen und damit auch von dem, was sie selber als Erwachsene sein werden. Das Kindsein selbst ist aber keine strikt zweiwertige Angelegenheit, die dritte Werte ausschließt. Wenn es zu einer zweiwertigen Beurteilung kommt (gute/schlechte Kinder, bestandene/nichtbestandene Prüfungen, gute/ 
schlechte Zensuren), geschieht dies aus Gründen der Selektion, nicht aus Gründen der Erziehung; und die Pädagogen reagieren mit pädagogischen Bedenken auf diese ihnen vermeintlich aufgezwungene Notwendigkeit.

Der Grund für dieses Codierdefizit liegt nicht in der organisch-psychischen Komplexität des mit „Kind“ bezeichneten Systems, denn solche Unangepaßtheiten findet man in allen binär codierten Systemen ebenfalls. Der Grund liegt in der Semantik, mit der die lose Kopplung dieses Mediums vorgestellt wird. In der Unterstellung von Lernfähigkeit/Lernwilligkeit wird die organisch-psychische Komplexität als offene, noch unbestimmte (oder unterbestimmte) Komplexität angenommen, aber die damit freigesetzten Möglichkeiten lassen sich nicht eindimensional schematisieren. Das wird mit Begriffen wie Freiheit, Selbsttätigkeit usw. honoriert und als pädagogisch unverzichtbarer Wert gehandelt. Mit Recht. Andererseits fehlt dem System damit aber die übliche Form, in der Funktionssysteme ihre Autopoiesis garantieren - eben die Zweiwertigkeit.

Das hat weitreichende Konsequenzen. Die binäre Codierung von Medien und Funktionssystemen stellt nämlich sicher, daß es auf alle Fälle weitergeht. Anders als bei teleologischen Systemen ist das eigene Ende (télos) nicht einprogrammiert, sondern offen gelassen. Man kann mit dem Positivwert (etwa Wahrheit), aber auch mit dem Negativwert (etwa Unwahrheit), etwas anfangen. Zwar ist nur der Positivwert im System anschlußfähig, aber der Negativwert kann spezifizieren, unter welchen Bedingungen (hier: Theorien) dies der Fall ist. Binär codierte Systeme sind daher immer eigendynamische, autopoietische Systeme, die ihr eigenes Ende nie mit ihren eigenen Operationen herbeiführen können. Da diese Bedingung für Pädagogen nicht gegeben ist, denken sie tendentiell teleologisch - sei es, daß sie ihre Ziele erreichen, sei es, daß sie sie abschwächen oder gar als im Einzelfall unerreichbar aufgeben müssen. Auf jeden Fall finden die Bemühungen um Exziehung irgendwann einmal ihr Ende.

Die Mediensemantik „Kind“ garantiert jedoch hinreichend, daß damit das System Erziehung nicht am Ende ist. Es wachsen immer neue Kinder nach. Außerdem wird durch Organisation sichergestellt, daß sie eingeschult werden und pünktlich zum Unterricht erscheinen. Man hat keine Zweifel, daß im nächsten Jahr wieder eine neue Klasse für Schulanfänger eingerichtet werden kann, und über Organisation kann man sich auch demographischen Schwankungen anpassen. Daß überhaupt Kinder geboren werden, wird als so sicher unterstellt, daß das Erziehungssystem sich nicht auf den Ausfall kompletter Geburtsjahrgänge einstellen und sich insofern auch nicht als umweltdeterminiert beschreiben muß. Die Autopoiesis des Systems wird über Organisation hinreichend gewährleistet. Zwar ist diese Abhängigkeit von Organisation unter dem Namen „Bürokratie“ ein laufendes Ärgernis für an Kindern (und nicht nur an ihren ,Stellen") interessierte Pädagogen; aber das sind dann gleichsam die Kosten für den strukturell erzwungenen Verzicht auf binäre Codierung. Während andere Funktionssysteme sich über binäre Codierung ausdifferenzieren und Organisation (etwa in der Form von Produktionsbetrieben, staatlichen Verwaltungen, Sportvereinen, Gerichten, Museen etc.) nur an systematisch 
später Stelle, nur als Bedingung für ausreichende Komplexität einführen müssen (und dann freilich auch davon abhängig werden), ist im Falle des Erziehungssystems die Ausdifferenzierung selbst von Organisation abhängig.

\section{$X I$.}

Mit all dem sind nur erste Schritte getan zu einer Klärung der Frage, ob und in welchem Sinne man von einem Medium des Erziehungssystems sprechen kann. Im allgemeinen Kontext einer Theorie symbolisch generalisierter Kommunikationsmedien fallen nun gewisse Ähnlichkeiten auf, aber auch eklatante Unterschiede. Der auffälligste Unterschied dürfte im Fehlen einer binären Codierung liegen, die im Erziehungssystem zwar für Zwecke der Selektion, nicht aber für Erziehung im eigentlichen Sinne ausgebracht werden kann. Das erklärt einerseits den von Pädagogen immer wieder bedauerten und abgelehnten Einfluß des Selektionscodes auf das Erziehungsgeschehen. Zweiwertigkeit hat eine unbestreitbare Faszination, der auch der Schulunterricht mehr oder weniger erliegt. Trotzdem kann das Problem, das heißt die Unwahrscheinlichkeit erzieherischer Kommunikation, nicht durch den Selektionsmechanismus allein angegangen werden. Das Problem liegt in der kommunikativen Unerreichbarkeit psychischer Systeme. Diese operieren faktisch als strukturdeterminierte Systeme, als zwar strukturell über Sprache gekoppelte, aber durch nicht spezifizierbare Systeme, als selbstreferentielle Systeme, als operativ geschlossene Systeme; und es ist nicht nur eine theoretische Frage, wenn man überlegt, wie Erziehung dann trotzdem möglich ist, das heißt: woher sie den Mut nimmt, sich für möglich zu halten und mit Kommunikation zu beginnen. Eine Antwort auf diese Frage liegt in dem Konstrukt des Kindes, jenes sichtbar noch nicht erwachsenen Wesens, das, wie man meinen kann, der Erziehung bedarf. Die evidente Offensichtlichkeit dieser Beobachtung verdeckt all das was entgegensteht. Und wenn Erziehung, und besonders: wenn Unterricht einmal anläuft, kommt ein autopoietisches System eigener Art in Gang, das die Elemente, nämlich die kommuikativen Operationen, aus denen es besteht, sich selber verdankt.

$\mathrm{Daß}$ das Erziehungsmedium technisch nicht annähernd so leistungsfähig ist wie beispielsweise Geld, ist durch das Fehlen einer binären Codierung leicht zu erklären. Auch fehlt jede Parallele zu jenen hochentwickelten Formen ökonomischer Rationalität, die sich aus der Reduktion auf die Entscheidung über Zahlungen oder deren Unterlassen bei gegebenen Preisen ergeben. Der Rationalitätsdefekt, der im Vergleich zum Geldmedium auffällt, wird dann nur allzu schnell durch Emphase, Überschwang und Enttäuschung ausgeglichen. Vor allem erklärt dieser Unterschied die hohe Interaktionsintensität der Erziehung, verglichen mit den extrem reduzierten Interaktionsformen, die die Geldwirtschaft allenfalls noch braucht. In diesem Vergleich gesehen, müssen die Medien-Defekte der Erziehung durch Interaktion unter Anwesenden ausgeglichen werden; und zwar durch Interaktion deshalb, weil dies die einzig angemessene Form des Umgangs mit „Kindern“ ist.

Diese spektakulären Unterschiede von Wirtschaft und Erziehung (und man 
könnte zum Vergleich auch Wissenschaft, auch Politik, auch Recht heranziehen) sollten nicht verdecken, daß es in all diesen Fällen um die Ausdifferenzierung von autonomen, operativ geschlossenen Funktionssystemen geht. Es scheint, daß für eine solche Evolution die Entwicklung spezifischer Kommunikationsmedien eine unerläßliche Bedingung ist, denn wie anders könnten systemspezifische Formdifferenzen entstehen und den jeweiligen Funktionen zugeordnet werden? In all diesen Fällen realisiert sich die Differenzierungstypik der modernen Gesellschaft; und nur die Art und Weise, in der das ermöglicht wird, variiert von Funktionssystem zu Funktionssystem.

\section{Anmerkungen}

1 Dazu NikLas Luhmann/Karl Eberhard Schorr: Reflexionsprobleme im Erziehungssystem, Neudruck mit Nachwort 1988, Frankfurt 1988, S. 54.

2 Vgl. NikLas Luhmann, Codierung und Programmierung: Bildung und Selektion im Erziehungssystem. In: Ders.: Soziologische Aufklärung Bd. 4, Opladen 1987, S. $182-201$.

3 Zur Diskussion dieser Frage NikLas Luhmann/Karl Eberhard Schorr (Hrsg.): Zwischen Technologie und Selbstreferenz: Fragen an die Pädagogik, Frankfurt 1982.

4 Siehe Klaus Prange: Bildung in dürftiger Zeit: Epochale Aspekte der pädagogischen Reflexion. In: Zeitschrift für internationale erziehungs- und sozialwissenschaftliche Forschung 5 (1988), S. 1-18.

5 Vgl. Nrklas Luhmann: Soziale Systeme: Grundriß einer allgemeinen Theorie, Frankfurt 1984; ders., Die Autopoiesis des Bewußtseins. In: Alors HAHN/Volker KAPP (Hrsg.): Selbstthematisierung und Selbstzeugnis: Bekenntnis und Geständnis, Frankfurt 1987, S. 25-94; ders., Wie ist Bewußtsein an Kommunikation beteiligt? In: Hans Ulrich Gumbrecht/K. Ludwig Pfeiffer (Hrsg.): Materialität der Kommunikation, Frankfurt 1988, S. 884-905.

6 Eine solche Wendung in der Kommunikationstheorie vollzieht auch BenNy SHANON, Metaphors for Language and Communication. In: Revue internationale de Systémique 3 (1989), S. 43-59.

7 Vgl. hierzu Terry Winograd/Fernando Flores: Understanding Computers and Cognition: A New Foundation for Design, Reading Mass. 1986, insb. S. 76f. (Dt. Übers.: Erkenntnis Maschinen Verstehen, Berlin 1989). Im Anschluß an HeIDEGGER, GADAmer, SeARLE, Maturana werden hier zwar alle „rationalistischen“ Vorstellungen zweckgerichteter Übertragungseffektivität aufgegeben; aber der Sinn von Kommunikation wird im Anschluß an SEARLE und MaTURANa dennoch primär in der Verhaltenskoordination bzw. in der Erzeugung von Bindungen (commitments) der beteiligten Individuen gesehen. Das käme dem Selbstverständnis der Pädagogen immer noch näher als die Variante von Systemtheorie, die wir im Text präsentieren.

8 Vgl. Fritz Heider, Ding und Medium. In: Symposium 1 (1926), S. 109-157.

9 Gotrhard GüNTHER nennt ihn „Designationswert". Siehe: Strukturelle Minimalbedingungen einer Theorie des objektiven Geistes als Einheit der Geschichte. In: GOTTHARD GÜNTHER: Beiträge zur Grundlegung einer operationsfähigen Dialektik, Bd. 3, Hamburg 1980, S. 136-182 (140ff.).

10 Siehe dazu an Hand eines bekannten Textes AloIs HAHN: Das andere Ich: Selbstthematisierung bei Proust. In: Volker KapP (Hrsg.): Marcel Proust: Geschmack und Neigung, Tübingen 1989, S. 127-141.

11 Hierzu mit einem Ausblick auf Erziehung von Heinz von Foerster: Sicht und 
Einsicht: Versuche zu einer operativen Erkenntnistheorie. Braunschweig 1985, S. 12f., $21 \mathrm{f}$.

12 Hierzu Ranulph Glanyille: Inside Every White Box There Are Two Black Boxes Trying to Get Out. In: Behavioral Sciences 27 (1982), S. 1-11, dt. Übers. in GlaNviLLE: Objekte, Berlin 1988. S. 119-147.

13 Vgl. Heinz von FoERSTer: Principles of Self-Organization - In a Socio-Managerial Context. In: Hans Ulrich/Gilbert J.B. Probst (Hrsg.): Self-Organization and Management of Social Systems: Insights, Promises, Doubts, and Questions, Berlin 1984, S. 2-24.

14 Philıppe Arıès: L'enfant et la vie familiale sous l'ancien régime, Paris 1960. Dt. Übers.: Geschichte der Kindheit, München 1975.

15 Laws of Form, 2. Aufl. London 1971.

16 Gegenbegriff "Trivialmaschine“ (Heinz von FoERster), die nach Maßgabe einer Transformationsfunktion Inputs in Outputs umsetzt und dies (ohne ihren jeweiligen Zustand damit zu beeinflussen) auf immer gleiche Weise tut, solange die Transformationsfunktion identisch bleibt. Organische und psychische Systeme sind keine Trivialmaschinen, sondern selbstreferentielle (historische) Maschinen - auch wenn Erzieher sich im Unterricht bemühen, sie in verläßliche (Fragen „richtig“ beantwortende) Trivialmaschinen zu transformieren. Hierzu auch NikLaS LuHMAnN: Codierung und Progammierung a. a.O. S. $192 \mathrm{ff}$.

17 Dies hängt damit zusammen, daß die strukturelle Komplexität eines Systems geringer ist als die operative Komplexität und deshalb Beobachtungs- und Beschreibungsvorteile bietet. Vgl. Lars LöFGREN: Complexity of Descriptions of Systems: A Foundational Study. In: International Journal of General Systems 3 (1977), S. $197-214$.

18 Wer wissen will, wie das im Bewußtsein vor sich geht, wenn es, ohne aktuell an Kommunkation mitzuwirken, sprachförmig denkt, lese etwa SAMUEL BeCKETTS "Comment c'est", oder auch "L'innomable".

19 Siehe Humberto R. Maturana: Erkennen: Die Organisation und Verkörperung von Wirklichkeit: Ausgewählte Arbeiten zur biologischen Epistemologie, Braunschweig 1982, S. $143 \mathrm{ff}$., $150 \mathrm{ff} ., 243 \mathrm{f}$., $251 \mathrm{ff}$.

20 Was, wie man vermuten muß, in einer Gesellschaft plausibel sein mußte, in der die vom Vater beauftragten Erzieher zumeist niedrigeren Standes waren als der Zögling.

$21 \mathrm{Daß}$ freilich gerade die beginnende Pädagogik so viel Verantwortung auch nicht wollen kann, läßt sich im 18. Jahrhundert mit durchgehenden Rückgriffen auf Natur vielfältig belegen, und sie findet sich damit im Einklang mit allgemeinen Zeitstimmungen, die in der Rückbuchung auf Natur die schwindelerregende Vorstellung zu vermeiden suchen, daß die Gesellschaft ein sich selbst produzierendes (autopoietisches) System sei. „Il faut s'approcher des berceaux pour connoitre ce que veut la nature", heißt es zum Beispiel bei BAUDOT DE JUILlET: Dialogues entre Messieurs Patru et d'Ablancourt sur les Plaisirs, Bd. 1, Amsterdam 1714, S. 92. In dieser Hinsicht ist denn auch Rousseau eher ein später, jedenfalls kein innovativer Autor.

22 Der Ausdruck ist viel älter als im Historischen Wörterbuch der Philosophie s.v. Perfektibilität angegeben. Vgl. z. B. Aegidius Columae Romanus, De Regimine Principum, 1277/79, zit. nach der Ausgabe Rom 1607, S. 52, bezogen auf Intellekt. Aber eine terminologische Breitenwirkung entfaltet er erst seit der Mitte des 18. Jahrhunderts.

23 Mit Recht hat man den Begriff deshalb mit dem das 18. Jahrhundert auch sonst faszinierenden Begriff der Materie verglichen: „La perfectibilité est la matière de la culture et de l'histoire et non son ressort" 
genèse: regards sur la théorie du devenir de l'entendement au XVIII e siècle: In: Cahiers pour l'analyse 4 (1966), S. 47-82 (62).

$24 \mathrm{Im}$ übrigen auch die auf Rousseau folgenden Bildungsromane. Vgl. dazu GEorG STANITZEK, Bildung und Roman als Momente der bürgerlichen Kultur: Zur Frühgeschichte des deutschen Bildungsromans. In: Deutsche Vierteljahrsschrift für Literaturwissenschaft und Geistesgeschichte 62 (1988), S. 416-450.

25 So August Hermann Niemeyer: Grundsätze der Erziehung und des Unterrichts, Halle 1796, Neudruck Paderborn 1970, S. 73.

26 Zur daran anschließenden Mediendifferenzierung vgl. NikLas LuHManN, Einführende Bemerkungen zu einer Theorie symbolisch generalisierter Kommunikationsmedien. In: Ders.: Soziologische Aufklärung Bd. 2, Opladen 1975, S. 170-192.

27 Die Anregung zu dieser Präzisierung des Mediums Erziehung verdanke ich KIAUs GilgenmanN: Die zunehmende Unwahrscheinlichkeit der intergenerativen Kommunikation, Osnabrücker Sozialwissenschaftliche Manuskripte 5/88, S. $24 \mathrm{ff}$. (GILGENMANN wählt für die gleiche Fragestellung einen anderen Ausgangspunkt in den zunehmenden Problemen der Kommunikation zwischen den Generationen und spricht von „Bildungsmedium" als Institutionalisierung der Lösung dieses Problems).

28 Madame de Sablé beispielsweise fordert, bei der Wahl von Beispielen auf das Auffassungsvermögen der Kinder Rücksicht zu nehmen ,en s'accomodant à eux, par des exemples clairs, communs et proportionnez à leur âge et leur esprit naturel" (so im Traktat „Pour les Enfants qu'on ne veut pas faire étudier à fonds“, abgedruckt In: N. Ivanoff, La Marquise de Sablé et son salon, Paris 1927, S. $150 \mathrm{ff}$. (Zitat S. 150).

29 Vgl. Niklas Luhmann: Liebe als Passion: Zur Codierung von Intimität, Frankfurt 1982 , S. $21 \mathrm{ff}$.

30 Vgl. aber auch Klaus Prange: Lernziel Lernen - Zur Kunst des Umlernens. In: Pädagogik und Schule in Ost und West 34 (1986), S. 84-90.

31 Ich meine das auch wörtlich: re-vidiert werden.

32 Andere Formen sind Entropie/Negentropie. Auch ist der Zusammenhang mit Problemen der Informationsverarbeitung und mit Bedingungen der Voraussehbarkeit (Grenzfall: Trivialmaschine) anmerkenswert.

33 Die Sinnform „Situation" bzw. „Welt" ist, das sei noch angefügt, genau darauf abgestimmt, daß sie nur in Momenten (aber auch: in jedem Moment) benötigt wird, in denen das System seine Autopoiesis realisiert. Deshalb diese Grenzbegriffe, die sich im Erleben beliebig verschieben; deshalb diese formlosen Formen, die keine Außenseite mehr kennen. Siehe dazu aus kybernetischer und differenztheoretischer Sicht auch Ranulph Glanville: Objekte a.a. O., insb. S. $149 \mathrm{ff}$. und S. $167 \mathrm{ff}$.

34 Siehe hierzu - übrigens auf Grund der Ausgangsvorstellung des Kindes als eines „leeren Behälters“" (angeîon kenón) - die Unterscheidung von Wissen Besitzen und Wissen Haben (wie immer man kektêsthai/échein übersetzen will) bei PLATON, Theaetet 197 Bff. Im einen Falle geht es um das Resultat eines Erwerbs, im anderen Falle um das aktuelle Benutzenkönnen.

35 Hierzu auch NikLAs LuHMANN: Erziehender Unterricht als Interaktionssystem. In: JÜRGEN DIEDERICH (Hrsg.): Erziehender Unterricht - Fiktion und Faktum, Frankfurt 1985, S. $77-94$.

36 „Potentialisiert“ im Sinne von Yves BareL, Le paradox et le système: Essai sur le fantastique social, 2. Aufl. Grenoble 1989, S. 71f., 185f,, $302 \mathrm{f}$.

37 Nach diesen Klarstellungen liegt auf der Hand, daß PLATONS Unterscheidung von Wissen Besitzen / Wissen Haben (s.o. Anm. 34) auf die alphabetische Schrift reagiert.

38 Zur Künstlichkeit und zur historischen Genese dieser Zweitbeobachtung des Wis- 
sens mit Hilfe der Unterscheidung wahr/unwahr siehe YeHuda Elxana, Das Experiment als Begriff zweiter Ordnung. In: Rechtshistorisches Journal 7 (1988), S. 244-271.

39 Siehe in einem allgemeineren Kontext der Frage nach situationspraktischem Umgang mit Quantitäten JeAn Lave: The Values of Quantification, in JoHN LAw (Hrsg.): Power, Action and Belief: A New Sociology of Knowledge? London 1986, S. 88-111. Speziell zu Untersuchungen an Kindern bzw. Schülern TerezINHA Nunes Carraher/David Wilitam Carraher/Analúcia Dias Schliemann: Mathematics in the Streets and in Schools. In: British Journal of Developmental Psychology 3 (1985) S. 21-29; Terezinha Nunes Carraher/Analúcia Dias Schliemann: Computation Routines Prescribed by Schools: Help or Hindrance?. In: Journal for Research in Mathematics Education 16 (1985), S. 37-44; Terezinha Nunes CarRaher/David William Carraher/Analúcta Dias Schliemann: Written and Oral Mathematics. In: Journal for Research in Mathematics Education 18 (1987), S. 83-97; dies., Mathematical Concept in Everyday Life. In: G. B. SAxe/M. GearHART (Hrsg.): Children's Mathematics, San Francisco 1988, S. 71-87.

40 Siehe hierzu Jürgen DIEDERICH: Didaktisches Denken: Eine Einführung in Anspruch und Aufgabe, Möglichkeiten und Grenzen der Allgemeinen Didaktik. Weinheim 1988, S. 42ff., insb. S. $58 \mathrm{ff}$.

41 Für ein Erziehungssystem, das noch gegen Ende des 19. Jahrhunderts in dieser Weise operierte, siehe Amanda F. Wood; Knowledge Before Printing and After: The Indian Tradition in Changing Kerala, Delhi 1985.

42 Siehe Wood a. a. O., S. $5 \mathrm{ff}$.

43 Und zwar in Europa aufgrund von primär marktwirtschaftlichen Mechanismen der Verbreitung von Büchern bereits im frühen 16. Jahrhundert. Vgl. dazu Micifael GIESECKE: Der Buchdruck in der frühen Neuzeit: Eine historische Fallstudie über die Durchsetzung neuer Informations- und Kommunikationstechnologien, Habilitationsschrift Bielefeld 1988.

44 Siehe WolfGang KlafkI: Die Bedeutung der klassischen Bildungstheorie für ein zeitgemäßes Konzept allgemeiner Bildung, Zeitschrift für Pädagogik 32 (1986), S. $455-476$.

45 Vgl. Luhmann/Schorr: Reflexionsprobleme a. a. O., S. $84 \mathrm{ff} ., 103 \mathrm{ff}$.

46 Aber auch dies scheint möglich zu sein. Vgl. Dieter Lenzen: Mythologie der Kindheit: Die Verewigung des Kindlichen in der Erwachsenenkultur: Versteckte Bilder und vergessene Geschichten, Reinbek 1985.

47 Und an dieser Beobachtung (siehe o. Anm. 45) möchte ich trotz der gegenwärtig zu bemerkenden Renaissance von "Geisteswissenschaften" und Bildungsbegrifflichkeit festhalten.

\section{Abstract}

\section{The Child as Medium of Education}

Inquiries into the medium of education take up a question which has so far usually been answered teleologically or psychologically. The coherence of educational endeavors was illustrated by their objective and this again was illustrated by the changes in the state of the educatees. This leads to the difficulty that no educator is able to known the inner state of the educatee, i.e. that which the latter really experiences, remembers, and expects during the process of education. And the drawback of all teleology is that it does not provide a concept for the frequent failure of these efforts. This kind of theory can be replaced by the distinction between medium and form.

\section{Anschrift des Autors:}

Prof. Dr. Niklas Luhmann, Universität Bielefeld, Fakultät für Soziologie, Postfach 8640, D-4800 Bielefeld 1. 